\title{
Kinetic based simulation of fixed bed gasifier and performance study on syngas production from different biomass feed-stocks
}

\author{
Bedewi Bilal, Solomon Workneh Fanta*, Neela Satheesh \\ Faculty of Chemical and Food Engineering, Bahir Dar Institute of Technology, \\ Bahir Dar University, Ethiopia. P.O. Box 26, Bahir Dar.
}

\begin{abstract}
Biomass is one of the most clean and renewable energy resources. In recent times, researchers have given more attention to biomass due to its zero emission of greenhouse gases such as carbon monoxide. In biomass utilization technologies, biomass gasification is an attractive mechanism for utilization of waste biomass generated from different agro-industries. Despite the application of fixed bed flow gasification on a large scale, the reaction rate in the hot conversion zone is almost unknown. However, knowledge regarding the rates of the gasification reaction at high temperature and high pressure is crucial for detailed design and optimization of these gasifiers. The study focused on the simulation of biomass (coffee bean and rice) husk gasification process based on the kinetics of the gasifier in order to investigate the produced syngas composition. The AspenPlus simulation was used to investigate the effect of operating parameters on the composition of the produced gas. Effect of different proportions of the simulation parameter includes gasification temperature, pressure, reactor volume, equivalence ratio and moisture on gas production and composition. Results of sensitivity analysis showed that an increase in temperature led to a rise in the production of $\mathrm{H}_{2}$ and $\mathrm{CO}$ gases. Whereas, an increase in moisture content of the biomass showed lower heating value of the produced gas. Based on the obtained result, the maximum lower heating value of syngas was obtained at the gasification temperature of $800^{\circ} \mathrm{C}$, steam to biomass ratio of 0.1 , pressure of 1 bar, $0.05 \%$ of moisture content and $0.02 \mathrm{~m}^{3}$ of reactor volume.
\end{abstract}

Keywords: AspenPlus, Biomass, Equivalence Ratio, Fixed Bed Gasifier, Kinetics

DOI: https://dx.doi.org/10.4314/ejst.v11i3.2

*Corresponding author: solworkneh@gmail.com 


\section{INTRODUCTION}

The price of fossil fuel (oil and natural gas) is constantly increasing, and energy crisis is continuously rising because of high energy demand from the contemporary world (Alison et al., 2018). On the other hand, there is an increase in demand globally for energy which is environmentally friendly and cheap. Biomass is one of the choices among this kind of energy resources since it is abundantly available, cheap, renewable and environmentally friendly (Ke, 2014). Compared with fossil fuels, biomass has lower $\mathrm{NOx}$ and $\mathrm{SO}_{\mathrm{x}}$ emission while it also has no net $\mathrm{CO}_{2}$ emission (Emma et al., 2010).

Biomass gasification process has been developed as a potential solution to rural electrification in developing countries through decentralized power generation (Dasappa, 2011). Gasification is a thermochemical process that converts organic or fossil based carbonaceous material into a combustible gas by reaction with different materials under certain range of temperature and controlled amount of air with a combination of steam (Ayhan, 2004). This process requires gasifying agent like air, oxygen, steam and $\mathrm{CO}_{2}$, which provides oxygen for the formation of $\mathrm{CO}$ from solid carbon in the biomass (Schuster et al., 2001). Gasification usually begins with drying sub-zone, followed by pyrolysis, a process that leads to the breakdown of the biomass into solid matter (charcoal), gaseous mixture (mainly $\mathrm{CO}_{2}, \mathrm{CO}, \mathrm{CH}_{4}$ and $\mathrm{H}_{2}$ ) and liquid matter (tar). The main focus of biomass gasification process is to efficiently convert the entire char constituent to a gaseous product of the syngas using either steam or $\mathrm{CO}_{2}$ (Cornelius et al., 2015).

Biomass is a by-product of agricultural practice and is produced by photosynthesis in plants. It is one of the most abundant renewable resources that can be used for sustainable syngas production (Chittaranjan, 2012). Biomass gasification is one of the most popular processes which help to reduce the environmental hazards brought by load of raw biomass. It also helps in reducing the net greenhouse gas emission, thereby moderating global warming (Buljit et al., 2013). Biomass gasifying reactors are complex facilities whose various operating conditions are difficult to investigate (Van et al., 2001). The 
characteristics of biomass greatly influence the performance of a biomass gasifier. A proper understanding of the physical and chemical properties of biomass feedstock is essential for the design and reliable operation of a biomass gasifier. There are numerous models for biomass gasification process (Chunshan, 2003). These models can be categorized into thermodynamic equilibrium models and kinetic models. The thermodynamic equilibrium models, also known as zero-dimensional models, are widely used by different researchers to predict the composition of the produced syngas and the equilibrium temperature by assuming the equilibrium level of chemical reactions (Maria et al., 2010). However, these models failed to provide accurate results and concentration or temperature profiles inside the reactor (Oliver et al., 2011). Kinetic models, on the other hand, provide essential information on the kinetics of chemical reactions involved in the biomass gasification, which are crucial in designing, evaluating and improving the gasifiers (Avdhesh, 2008). These models are based on the chemical reaction rates and are able to predict both overall produced gas yield and compositions based on the time and location within the gasifier. However, as the models involve a number of reactions and transfer processes, the models computationally get more intensive (Avdhesh, 2008).

Gasification is expected to be the future method of producing an energy carrier, and the production of syngas from biomass or waste would require gasification process as an essential part of the overall process. Current gasifiers can be classified into two types: fixed-bed and fluidized-bed (Ke, 2014). Fluidized-bed gasification is often adopted for larger capacity of biomass feedstock. It is so complicated in construction and operation that it requires higher investment (Andre, 2006). Kinetic simulation of fixed-bed gasification, which was chosen for the current study, is not only economical but also suitable for any type of biomass. It also has the advantage of a small amount of fly ash production while the syngas can be used in various areas as clean energy (Chen et al., 2010).

Even if gasification process is an eco-friendly energy production process, identifying the thermo-chemical processes and syngas composition 
inside the gasifier at different stages of gasification process is difficult. Moreover, as noted before, the characteristics of biomass greatly influence the performance of a biomass gasifier. It is thus impossible to know the composition and thermo-chemical property of the produced syngas until experimental investigation of the gasification process is conducted. Worse still, experimental work is both capital intensive and time consuming. Therefore, it is better to use a simulation process to investigate the composition of the syngas by using elemental analysis of the feed-stock. The simulation can be performed by using any chemical engineering software designed for research and educational purpose. Such software was used to quantify the chemical and physical process of the biomass inside the gasifier operated under different parameters. The objective of this study was to develop a kinetic simulation model for investigating syngas production from the selected biomass feed-stock by using Aspen Plus software.

\section{MATERIALS AND METHODS}

\section{Raw material collection}

The raw materials used in this study were agricultural residues (coffee bean husk and rice husk) locally produced on farmlands in Ethiopia. These materials were collected from crop fields and local communities around Bahir Dar, Ethiopia. The chemistry of biomass gasification is similar to that of coal gasification such that the general chemical formula used for the coffee bean husk was $\mathrm{CH}_{1.76} \mathrm{O}_{0.78} \mathrm{~N}_{0.03}$ and the rice husk was $\mathrm{CH}_{1.64} \mathrm{O}_{0.95} \mathrm{~N}_{0.005}$. Therefore, stoichiometric air required for complete oxidation of coffee bean husk was calculated from the reaction and determined that $8.37 \mathrm{~kg}$ of air was required for complete combustion of $1.5 \mathrm{~kg}$ of coffee bean husk.

\section{Biomass feedstock characterization}

\section{Proximate analysis}

Proximate analysis was conducted following standardized procedures (ASTM E872, ASTM D1102 and ASTM) to determine composition of a 
fuel, average percentage of volatile matter content, percentage of ash content, moisture content and fixed carbon percentage of the biomass.

\section{Moisture content \%}

The percentage moisture content was determined by hot air oven method. Known weight of biomass sample $\left(\mathrm{B}_{0}\right)$ was taken in moisture dish and oven dried at $105^{\circ} \mathrm{C}$ until constant weight of the sample $\left(\mathrm{B}_{1}\right)$ was obtained. The loss in weight was considered as the moisture content while sample left in the moisture dish were considered as total solids present in the sample. The change in weight $\left(\mathrm{B}_{2}\right)$ was then used to determine the sample's percentage moisture content by using the following equation 1 .

\section{Volatile matter (\%)}

$$
P M(\%)=\frac{B_{2}}{B_{0}} \times 100
$$

The percentage of volatile matter was determined by taking the known weight $\left(\mathrm{B}_{0}\right)$ of the pulverizing oven dried biomass sample in a crucible and placed at $550^{\circ} \mathrm{C}$ for 10 minutes in muffle furnace (Model BK - 5$12 \mathrm{GJ}$ ) until a constant weight was obtained. The weight of the crucible was noted (B1) after cooling in desiccators. The VM\% was then calculated by using the following equation 2 .

\section{Ash content (\%)}

$$
V M(\%)=\frac{B_{0}-B_{1}}{B_{0}} \times 100
$$

To determine the percentage of ash content, known weight $\left(\mathrm{B}_{0}\right)$ of the residue obtained after moisture content determination (dried biomass) was taken in open silica crucible. The crucibles with contents were kept at $550^{\circ} \mathrm{C}$ for 4 hours in muffle furnace (Model BK $-5-12 \mathrm{GJ}$ ). The crucibles weight was taken after being allowed for cooling in desiccator to obtain weight of ash (C); the ash content was determined by equation 3.

$$
A C(\%)=\frac{C}{B_{0}} \times 100
$$




\section{Fixed carbon (\%)}

The percentage of fixed carbon was computed by subtracting the sum of $\%$ volatile matter and $\%$ ash content from 100 as shown in equation 4 .

Fixed carbon $=100 \%-($ Ash content $\%+$ Volatile matter $\%)$

\section{Ultimate analysis}

This analysis was used to determine elemental composition $(\mathrm{C}, \mathrm{N}, \mathrm{H}, \mathrm{S}$, $\mathrm{O}$, etc.) of the biomass fuels, and the empirical formula of biomass was $\mathrm{C}_{n} \mathrm{H}_{m} \mathrm{O}_{x} \mathrm{~N}_{y}$ used to establish stoichiometric equation for complete combustion of biomass and equivalence ratio for the gasification reaction. It was carried out by using EA 1112 Flash CHNS/O-analyzer. To determine elemental analysis of the biomass, carrier gas flow rate of $120 \mathrm{ml} / \mathrm{min}$, reference flow rate of $100 \mathrm{ml} / \mathrm{min}$, oxygen flow rate of 250 $\mathrm{ml} / \mathrm{min}$, furnace temperature of $900^{\circ} \mathrm{C}$ and oven temperature of $75^{\circ} \mathrm{C}$ were used (Harmandeep et al., 2013). Bridgwater (2003) described the gasification sequence as drying, which is the process of removing moisture from the biomass, followed by pyrolysis. Finally, oxidation and reduction processes follow. Figure 1 illustrates the process of the gasifier, the fixed bed gasifier Aspen Plus process flow sheet.

\section{Drying sub-zone}

In this sub-zone the biomass feedstock receives enough thermal energy from hot zone downstream to release the water molecule associated with it. The rate of drying depends on the temperature, velocity, moisture content of the drying gas, external surface area of the feed material, internal diffusivity of moisture, nature of moisture bonding of the material and radioactive heat transfer. Typically, the moisture content of the biomass ranges from $5 \%$ to $35 \%$. Drying occurs at about $100-200^{\circ} \mathrm{C}$ with a reduction in the moisture content of the biomass to $<5 \%$ (Arnavat, 2011). Low density materials change dimensions slightly due to shrinkage and compression whereas negligible size changes were experienced by feedstock with high density. There was no chemical reaction in this zone (Sadaka, 2008). 


\section{Pyrolysis sub-zone}

This sub-zone was useful for the thermal decomposition of the biomass in the absence of oxygen or air. In this process the volatile matter in the biomass was reduced, which resulted in the release of hydrocarbon gases from the biomass and reduced to solid charcoal. The hydrocarbon gases can condense at a sufficient low temperature to generate liquid tar.

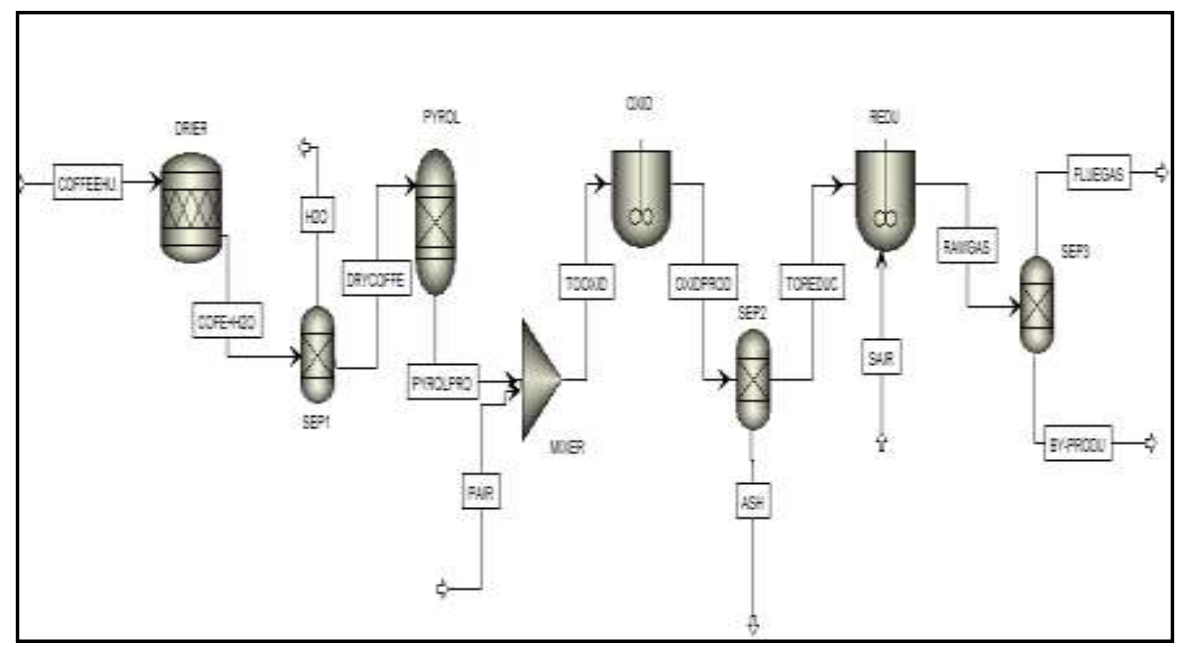

Figure 1. Fixed bed gasifier Aspen Plus process flow sheet

The reaction that occurred in this sub-zone is shown as follows:

$$
\begin{gathered}
\text { Biomass } \rightarrow \text { char }+ \text { tar }+ \text { volatiles } \\
\text { Volatiles } \rightarrow \mathrm{CH}_{4}+\mathrm{CO}+\mathrm{CO}_{2}+\mathrm{H}_{2}+\mathrm{H}_{2} \mathrm{O}
\end{gathered}
$$

\section{Oxidation sub-zone}

In this sub-zone there was a reaction between solid carbonized biomass and oxygen in the air, resulting in the formation of $\mathrm{CO}_{2}$. The hydrogen which is present in the biomass is also oxidized to generate water. A large amount of heat is released with the oxidation of carbon and hydrogen. If oxygen is present in sub-stoichiometric quantities, partial oxidation of 
carbon may occur, resulting in the generation of carbon monoxide (Arnavat, 2011).

\section{Reduction sub-zone}

Gasification could occur in any of the zones, but it was prevalent in the gasification zone due to the lack of an oxidizer (Muilenburg, 2011). In this sub-zone, due to the lack (or sub-stoichiometric presence) of oxygen, several reduction reactions occur at $800-1000^{\circ} \mathrm{C}$. The reaction that occurred in this sub-zone was mostly endothermic.

\section{Process simulation and model development}

Because of the reliability and precise outcomes in process modeling and simulation, Aspen Plus was used in this study to develop and simulate a fixed bed gasification process for coffee bean husk and rice husk as feedstock. Aspen is chosen because it is a very important data base to predict the result of the syngas produced from biomass feed stocks. The simulation process was based on the mass-energy balance and chemical kinetics for the overall process. It comprises several data containing physical, chemical and thermodynamic data for a wide variety of chemical compounds. Moreover, a selection of kinetic model was required for the accurate simulation of any given system (Zheng et al., 2003).

In Aspen Plus there is no particular gasifier model ready to use. Therefore, to model a fixed bed gasifier, it is necessary to separate the whole process into different blocks. The process and the main unit operations involved in the gasifier were drying, pyrolysis (decomposition), gasification and combustion. These were simulated by using the reactors RStoic, RYield and RCSTR. Reaction kinetic parameters were considered since the simulation in this study was based on kinetic modeling (Sadaka et al., 2002). The following assumptions were also considered in modeling the gasification process (equation 514). Gasification process was an isothermal and steady state while particles were spherical and not affected in the course of the reaction. The simulation was carried out with power-law kinetics. The residence time for reactant was sufficiently high to reach chemical equilibrium, and liquid modeling rather than solid modeling was considered for biomass 
due to unavailability of certain parameters. The gasification reactions which play a great role for the production of syngas from the pyrolysis sub-zone to combustion sub-zone were the following (Lv et al., 2005):

Oxidation reactions:
$\mathrm{C}+0.5 \mathrm{O}_{2} \rightarrow \mathrm{CO}$
$\Delta H=+123.1 \mathrm{KJ} / \mathrm{mol}$
$\mathrm{C}+\mathrm{O}_{2} \rightarrow \mathrm{CO}_{2}$
$\Delta H=+393.8 \mathrm{KJ} / \mathrm{mol}$
$\mathrm{CO}+0.5 \mathrm{O}_{2} \rightarrow \mathrm{CO}_{2}$
$\Delta H=+283.9 \mathrm{KJ} / \mathrm{mol}$
$\mathrm{H}_{2}+0.5 \mathrm{O}_{2} \rightarrow \mathrm{H}_{2} \mathrm{O}$
$\Delta H=+242 \mathrm{KJ} / \mathrm{mol}$

Boudouard reaction:

$\mathrm{C}+\mathrm{CO}_{2} \leftrightarrow 2 \mathrm{CO} \quad \Delta \mathrm{H}=+172.6 \mathrm{KJ} / \mathrm{mol}$

Water gas reaction:

$\mathrm{C}+\mathrm{H}_{2} \mathrm{O} \leftrightarrow \mathrm{CO}+\mathrm{H}_{2} \quad \Delta \mathrm{H}=+131.4 \mathrm{KJ} / \mathrm{mol}$

Methanation reaction:

$$
\mathrm{C}+2 \mathrm{H}_{2} \leftrightarrow \mathrm{CH}_{4} \quad \Delta \mathrm{H}=-74.9 \mathrm{KJ} / \mathrm{mol}
$$

Water gas shift reaction:

$\mathrm{CO}+\mathrm{H}_{2} \mathrm{O} \leftrightarrow \mathrm{CO}_{2}+\mathrm{H}_{2} \quad \Delta \mathrm{H}=-41.2 \mathrm{KJ} / \mathrm{mol}$

Methane reforming reaction:

$\begin{array}{ll}\mathrm{CH}_{4}+\mathrm{H}_{2} \mathrm{O} \leftrightarrow \mathrm{CO}+3 \mathrm{H}_{2} & \Delta \mathrm{H}=-206.3 \mathrm{KJ} / \mathrm{mol} \\ \mathrm{CH}_{4}+2 \mathrm{H}_{2} \mathrm{O} \leftrightarrow \mathrm{CO}+4 \mathrm{H}_{2} & \Delta \mathrm{H}=-165 \mathrm{KJ} / \mathrm{mol}\end{array}$

\section{Model description}

The Aspen Plus stoichiometric reactor, RStoic (model ID: DRIER), was used to simulate the evaporation of the moisture. At this gasification subzone, RStoic converted part of a feed to a form of water which required the extent of reaction known as: feed $\rightarrow 0.0555084 \mathrm{H}_{2} \mathrm{O}$.

In this step, the moisture of the feedstock was partially evaporated and then separated using a separator model Sep (model ID: SEP1) through split fraction of the components. Then, the dried feedstock was placed into the next region for decomposition after being separated from the 
evaporated moisture. The evaporated moisture was drained out from the process.

Decomposition (pyrolysis) is one of the main steps of the gasification process where the feedstock was decomposed into its elements. The Aspen Plus yield reactor, RYield (model ID: PYROL), was used to simulate the decomposition of the feed. The yield reactor converted nonconventional feed into conventional components. In this step, feed was converted into different components including $\mathrm{C}, \mathrm{O}_{2}, \mathrm{~N}_{2}, \mathrm{H}_{2}, \mathrm{~S}$ and ash by specifying the yield distribution according to the feedstock's ultimate analysis. The decomposed elements mixed with air at an Aspen MIXER block were ready for gasification.

The Aspen Plus CSTR reactor, RCSTR, performs char gasification by using reactor kinetics. RCSTR assumes perfect mixing in the reactor; that is, the reactor contents have the same properties and composition as the outlet stream. RCSTR handles kinetic and equilibrium reactions as well as reactions involving solids. Therefore, for char gasification it was preferred A separator model Sep (model ID: SEP2), which was used to separate the ash from the gas mixture using split fractionation of the components. To complete the gasification process, another RCSTR reactor was used in the combustion section with minimum air mixing. This combustion process was also based on the principle of reactor kinetics. To identify the syngas components from by-products, a separator model, Sep (model ID: SEP3), was used (Sharmina et al., 2013).

\section{Model sequence}

A number of Aspen Plus units were used to develop the model. In this study, the main processes were simulated by three reactors in Aspen Plus: RStoic, RYield and RCSTR. The gasification processes began with the decomposition (pyrolysis) region and continued with the combustion region.

\section{Stream classes and sub-streams}

Stream classes were used to define the structure of simulation streams when inert solids were present. The default stream class for most 
simulations is CONVEN. The CONVEN stream class has a single substream: the MIXED sub-stream. By definition, all components in the MIXED sub-stream participated in phase equilibrium whenever flash calculations were performed. To introduce inert solid components to a simulation, one or more additional sub-streams were included. Aspen Plus has two other types of sub-streams available: the CISOLID substream type and the NC sub-stream type. The CISOLID sub-stream (Conventional Inert Solid) was used for homogeneous solids that have a defined molecular weight. In contrast, the NC sub-stream (Nonconventional) was used for heterogeneous solids that have no defined molecular weight. Both the CISOLID sub-stream and the NC sub-stream, however, provide the option of including a Particle Size Distribution (PSD) for the sub-streams, which were combined in different ways to form different stream classes. MIXNCPSD stream class contains two sub-streams: MIXED and NCPSD. The default stream class of the Solids application type, MIXCISLD, was insufficient for the simulation since there is NC sub-stream with a PSD for the biomass. In simulation of fixed-bed gasifier, the stream class was specified as MIXCINC because particles are spherical and are not affected in the course of the reaction (Buekens et al., 1985).

\section{Physical property method}

For this fixed bed gasifier simulation process, Redlich-Kwong-Soave cubic equation of state with Boston-Mathias alpha function property method was selected as the global property method. It was used to estimate all physical properties of the conventional components in the gasification process. The enthalpy and density model selected for both feed and ash are non-conventional components, HCOALGEN and DCOALIGT. In this study, feed was defined as non-conventional component, and the above model was selected during the simulation process (Ergudenler, 1993).

\section{Specifying feed stream}

In this simulation, the biomass (coffee bean husk and rice husk) was specified as non-conventional. The biomass lower heating value (LHV) was also specified with the HCOALGEN and DCOALIGT property 
model chosen to estimate the biomass enthalpy of formation, specific heat capacity and density based on the ultimate and proximate analyses. Finally, the stream thermodynamic condition $\left(1\right.$ bar and $\left.25^{\circ} \mathrm{C}\right)$ and mass flow rate of $1.5 \mathrm{~kg} / \mathrm{hr}$ were used as input for the process model. The detailed specifications for the inlet stream in this gasification process are listed in Table 1.

Table 1. Specifications for the inlet streams in the process model*

\begin{tabular}{lll}
\hline Stream & Component & Mass flow rate \\
\hline Biomass & $\begin{array}{l}\text { Specified as its proximate, ultimate } \\
\text { and sulfur analysis }\end{array}$ & $1.5 \mathrm{~kg} / \mathrm{hr}$ \\
Primary air & $\begin{array}{l}21 \% \mathrm{O}_{2} \text { and } 79 \% \mathrm{~N}_{2} \\
\text { (mole fraction) }\end{array}$ & $0.3 \mathrm{~kg} / \mathrm{hr}$ \\
$\begin{array}{l}\text { Secondary } \\
\text { air }\end{array}$ & $\begin{array}{l}21 \% \mathrm{O}_{2} \text { and } 79 \% \mathrm{~N}_{2} \\
\text { (mole fraction) }\end{array}$ & $0.001 \mathrm{~kg} / \mathrm{hr}$ \\
\hline *Pressure was 1 bar for all cases and the temperature $25^{\circ} \mathrm{C}$.
\end{tabular}

\section{Specifying blocks}

After completing the specification of the inlet stream in the process simulation, all the blocks were specified according to the design operating condition.

\section{RESULTS AND DISCUSSION}

\section{Proximate and ultimate analysis}

The results for the proximate and ultimate analysis of both raw materials (rice and coffee husk) are presented in Table 2. The table shows averages of three analyses, which indicate that moisture content, fixed carbon, hydrogen, and nitrogen were reported in coffee husk than in rice husk. 


\section{Effect of gasification temperature on syngas composition}

Gasification temperature is one of the most influential factors affecting the product gas composition and properties. The effect of gasifier temperature on producing syngas composition is shown in Figure 2.

The temperature considered varied from $400^{\circ} \mathrm{C}$ to $1400^{\circ} \mathrm{C}$ for the biomass of $1.5 \mathrm{~kg} / \mathrm{hr}$ at $1 \mathrm{bar}$ of pressure. As gasification temperature increased, the concentration of $\mathrm{CO}$ and $\mathrm{H}_{2}$ increased, while $\mathrm{CO}_{2}$ and $\mathrm{CH}_{4}$ decreased (Figure 2). In short, the temperature of the gasifier was identified as important factor in the production of $\mathrm{H}_{2}$ rich gas from biomass.

These tendencies could be attributed to the laws of chemical reaction: higher temperature favors the products in endothermic reactions and the reactants in exothermic reactions. Because of these reactions, with the increase in the gasification temperature, the concentration of $\mathrm{CH}_{4}$ could decrease to the endothermic reaction, which is described in Eq. 13 and Eq. 14. The increase in $\mathrm{H} 2$ concentration is clarified by the endothermic reaction as described in equations 10,13 and 14 . The CO concentration increased (Figure 2) due to the exothermic reactions described in equations $9,10,13$ and14, which were more dominant than endothermic reaction, specified in equation 5. In endothermic reaction (as described in equation 14), energy is released and the concentration of $\mathrm{CO}$ increased and the $\mathrm{CO}_{2}$ concentration decreased with increasing gasification temperatures.

This is due to the fact that endothermic reaction, which is described in equation 9 , was more dominant, shifting the reaction towards the right and resulting in an increase in $\mathrm{CO}$ and a decrease in $\mathrm{CO}_{2}$ as the gasification temperature increased.

\section{Effect of gasification pressure on syngas composition}

Pressure was also one of the most important gasification factors that influence the composition of syngas production. The effect of gasifier pressure on produced syngas composition is shown in Figure 3 where the 
pressure varied from 1 to 10 bars. The result was examined by varying the pressure of the gasifier and keeping the other parameters constant.

\section{Effect of equivalence ratio on syngas composition}

In the gasifier simulation process, the effect of air-biomass ratio on the product gas composition was examined. The simulation results for the syngas composition versus air to biomass ratio covered a range of 0.2 to 1.0. The investigation was made at the fixed biomass flow rate of 1.5 $\mathrm{kg} / \mathrm{hr}$ and air mass flow ranged between 1.67 to $5.0 \mathrm{~kg} / \mathrm{hr}$ while the other gasification parameters remained unchanged (temperature and pressure).

As shown in Figure 4, the production of both $\mathrm{H}_{2}$ and $\mathrm{CO}$ decreased with an increase in amount of air. Air to biomass ratio not only represented the $\mathrm{O}_{2}$ quantity, which is introduced into the gasifier, but also affected the gasification temperature under the condition of auto thermal operation. This shows that higher air to biomass ratio could lead to low quality syngas due to increasing oxidation reaction. Alternatively, higher air to biomass ratio and higher gasification temperature accelerates gasification, thereby improving the product quality to a certain extent. The simulation result in Figure 4 indicates that $\mathrm{CO}_{2}$ concentration increased significantly from $5 \%$ to $20 \%$ due to an increase in air equivalent ratio; however, $\mathrm{CO}$ showed an inverse trend, decreasing from $45 \%$ to $1 \%$. This is because the increase in air equivalent ratio meant more oxygen was placed in Eq. 6, toward the right. At higher ratio, $\mathrm{CO}$ concentration decreased according to Eq. 6, which prevailed over Eq. 5, with the increase in air equivalence ratio. The $\mathrm{CH}_{4}$ concentration decreased as the ratio of air to biomass ratio increased. Similarly, the $\mathrm{H}_{2}$ concentration decreased according to Eq. 13 and Eq.14. To wit, the concentration of $\mathrm{H}_{2}$ in this simulation process decreased from $30 \%$ to $1 \%$ due to arise in air to biomass ratio.

\section{Effect of biomass moisture content on syngas composition}

The moisture content of the biomass was another factor that affected the composition of syngas produced from gasification process. This effect was examined by varying the moisture content from $5 \%$ to $35 \%$. 
Table 2. Proximate and ultimate analysis of feed used in simulation

\begin{tabular}{llllllllll}
\hline Feed stocks & \multicolumn{3}{l}{ Proximate analysis } & (weight \%, dry base) & \multicolumn{5}{l}{ Ultimate analysis (weight \%, dry base) } \\
\cline { 2 - 10 } & $\begin{array}{l}\text { Moisture } \\
\text { content }\end{array}$ & $\begin{array}{l}\text { Fixed } \\
\text { carbon }\end{array}$ & $\begin{array}{l}\text { Volatile } \\
\text { matter }\end{array}$ & Ash & Carbon & Hydrogen & Oxygen & Nitrogen & Sulfur \\
\hline Coffee husk & 9.65 & 28.28 & 58.37 & 3.7 & 43.39 & 6.37 & 45.08 & 1.41 & 0.05 \\
Rice husk & 6.15 & 13.98 & 65.04 & 14.83 & 35.36 & 4.83 & 44.68 & 0.21 & 0.09 \\
\hline
\end{tabular}

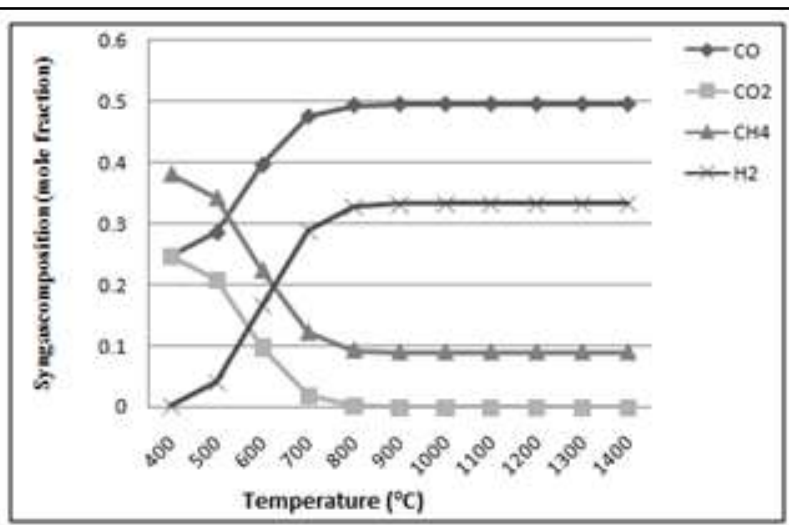

A

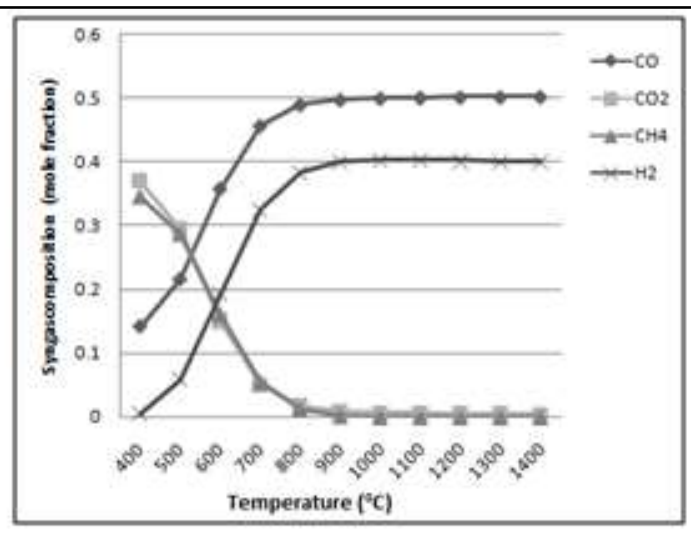

B

Figure 2. The effect of temperature on the syngas composition (A) for coffee bean husk and (B) for rice husk 


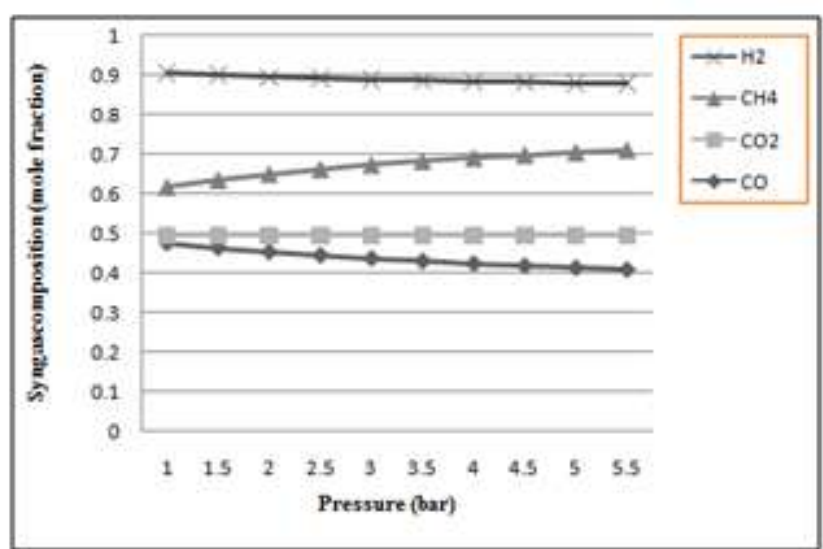

A

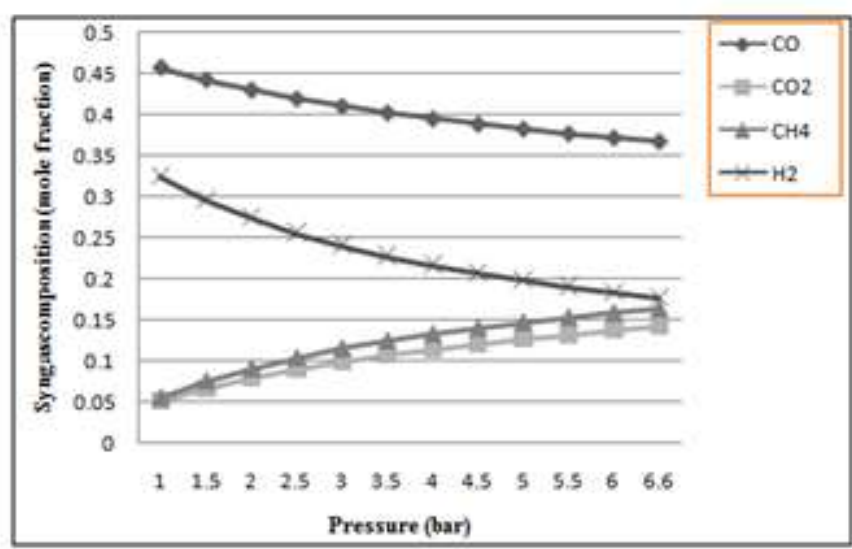

B

Figure 3. Effect of gasification pressure on syngas composition (A) for coffee bean husk and (B) for rice husk 


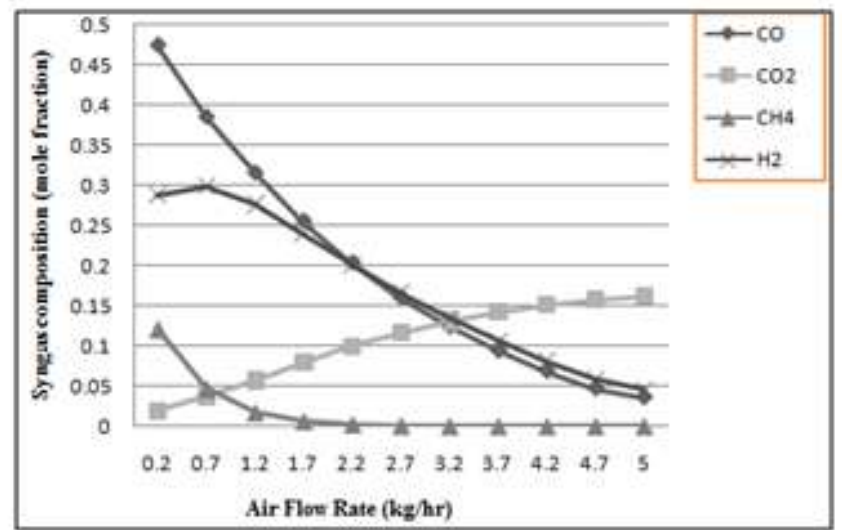

A

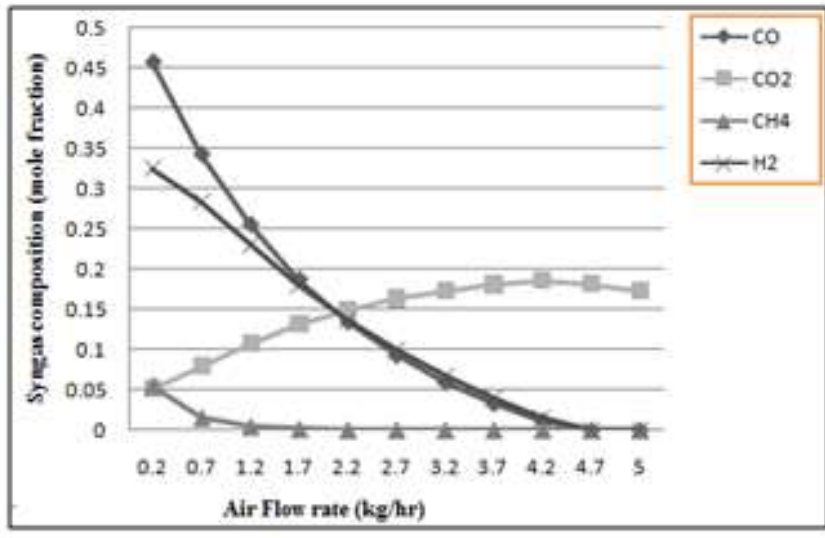

B

Figure 4. The effect of air flow rate on the syngas composition (A) for coffee bean husk and (B) for rice husk 
The high moisture content of the biomass led to a slight increase in the composition of $\mathrm{H}_{2}$ and $\mathrm{CO}_{2}$ of the syngas but to a decrease in $\mathrm{CO}$ and $\mathrm{CH}_{4}$ composition (Figure 5).

\section{Effect of reactor volume}

The reactor volume was also another factor that influenced the composition and yield of the syngas produced, which was analyzed by varying the reactor volume from 0.01 to $0.4 \mathrm{~m}^{3}$. The composition of $\mathrm{H}_{2}$ and $\mathrm{CO}$ increased in both biomass feedstocks with increasing reactor volume (Figure 6), while on the other hand, the composition of $\mathrm{CO}_{2}$ and $\mathrm{CH}_{4}$ was found independent of the volume of the reactor (Figure 6). The phenomena were due to endothermic reaction mechanisms shown in equation 15 and 16.

Boudouard reaction: $\mathrm{C}+\mathrm{CO}_{2} \leftrightarrow 2 \mathrm{CO} \Delta \mathrm{H}=+172.6 \mathrm{KJ} / \mathrm{mol}$

Water, gas reaction: $\mathrm{C}+\mathrm{H}_{2} \mathrm{O} \leftrightarrow \mathrm{CO}+\mathrm{H}_{2} \Delta H=+131.4 \mathrm{KJ} / \mathrm{mol}$

\section{Lower heating value (LVH) produced gas (syngas)}

The LHV of syngas depended on other operating parameters of the gasifier. As gas composition is affected by temperature, it in turn significantly affects the LHV of the produced gases. The best way to get a possible high LHV was to produce a gas mixture rich in $\mathrm{CO}_{2} \mathrm{CH}_{4}$ and $\mathrm{H}_{2}$ which could be suitable for energetic exploitation of internal combustion engines and turbines for the production of power. The LHV of the gas was calculated using equation 17 (Lv et al., 2004).

$$
L H V=\frac{\left(10110 * X_{C O}+119494 * X_{H_{2}}+49915 * X_{C H_{4}}\right) k J}{k g}
$$

Where $X_{C O}, X_{H_{2}}$ and $X_{C_{4}}$ were the mole fraction of producer gas.

The Lower Heating Value of the produced gas were $\mathrm{LHV}_{C O}=10,110$ $\mathrm{kJ} / \mathrm{kg}, \mathrm{LHV}_{\mathrm{CH} 4}=49,915 \mathrm{~kJ} / \mathrm{kg}$ and $\mathrm{LHV}_{\mathrm{H} 2}=11,949 \mathrm{~kJ} / \mathrm{kg}$ (Lars and Torbjörn, 2001). 
An increase in gasifier temperature is important to increase the heating value of the biomass, which is used in the simulation process (Figure 7). The concentration of $\mathrm{H}_{2}$, whose coefficient within the above equation is the largest implies that an increase in gasifier temperature tends to mean an increase in $\mathrm{H}_{2}$ and $\mathrm{CO}_{2}$ gas concentration. At the lower concentration and lower temperature, the heating value of the biomass increased fast. Sometime later, the heating value of both biomasses slightly increased. Both biomasses reached maximum heating value at the gasifier temperature of $800^{\circ} \mathrm{C}$. The heating value and the gasifier temperature have direct relationship. This means that a rise in temperature of the gasifier slightly increased the heating values.

The heating value obtained for the rice husk was $51,542.12 \mathrm{~kJ} / \mathrm{kg}$ and for the coffee $48,773.85 \mathrm{~kJ} / \mathrm{kg}$ (Figure 7). Increasing gasification pressure led to increased methane concentration. The result implies that the LHV of the syngas decreased (Figure 7B). The heating values of the biomass reached maximum at the lowest pressure but decreased at the highest pressure. In the higher ER, the concentration of the syngas with $\mathrm{CO}, \mathrm{H}_{2}$ and $\mathrm{CH}_{4}$ was dominant. The result shows that an increase in ER tends to bring about a decrease in the energy content of the produced gas.

The moisture content and the reactor volume were also factors, which influence the concentration of produced syngas. Regardless of the type of biomass, more biomass moisture content was associated with low syngas production. This may be due to a decrease in LHV. However, an increase in the reactor volume led to a higher concentration of $\mathrm{CO}, \mathrm{H}_{2}$ and $\mathrm{CH}_{4}$ in produced syngas. The lower heating value of the syngas increased as reactor volume increased (Figure 7D). The coffee husk gave higher heating value of $46,566.11 \mathrm{~kJ} / \mathrm{kg}$ than that of the rice husk of $42,455.84 \mathrm{~kJ} / \mathrm{kg}$, at reactor volume of $0.4 \mathrm{~m}^{3}$. The concentration of syngas increased with an increase in the gasification temperature and reactor volume. The concentration of combustible gas decreased with an increase in gasifier temperature, reactor volume, air equivalence ratio and moisture content. Nevertheless, an increase in pressure was associated with the concentration of methane gas and a lower heating value of the syngas concentration. 
Bedewi Bilal et al.

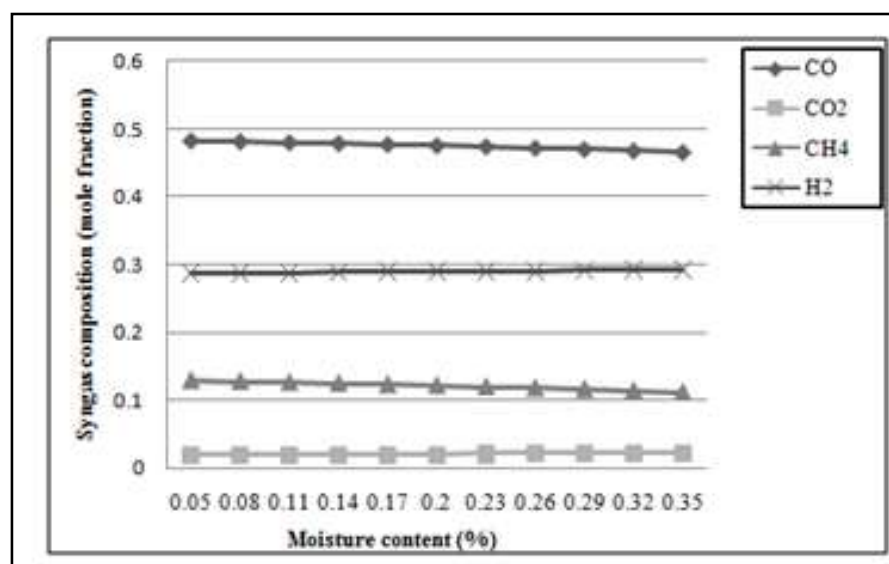

A

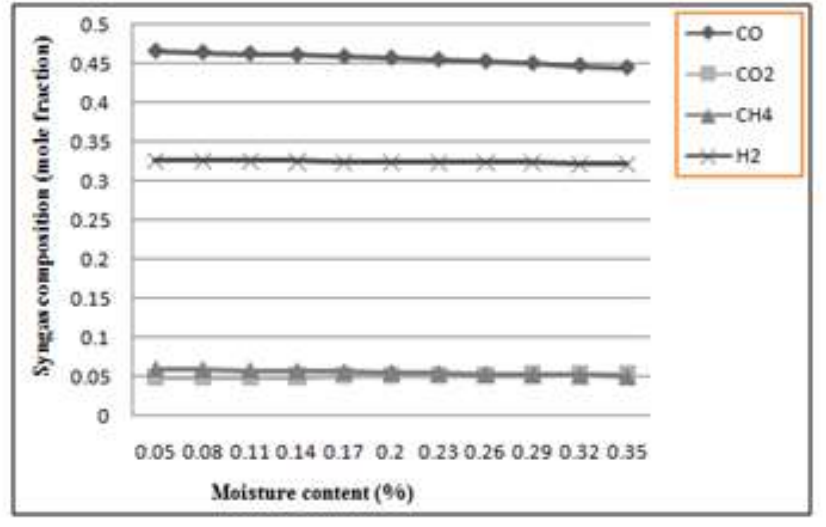

B

Figure 5. The effect of biomass moisture content on the composition of syngas (A) for coffee bean husk and (B) for rice husk 


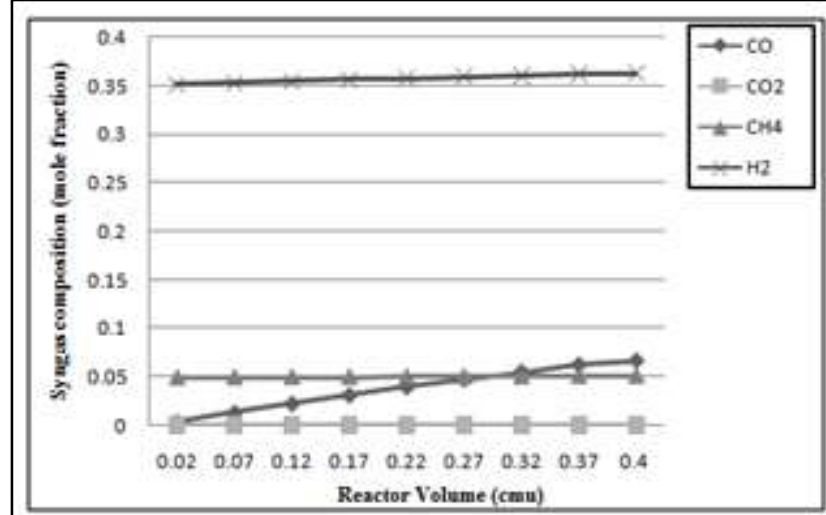

A

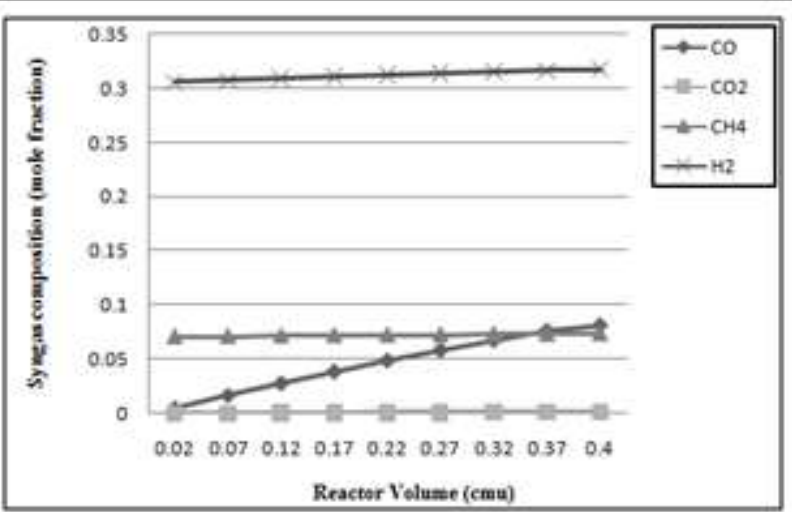

B

Figure 6. The effect of reactor volume in the syngas composition (A) for coffee bean husk and (B) for rice husk 


\section{Effect of steam to biomass ratio on syngas composition}

Introduction of the steam into the gasifier was another factor, which affected the composition of the syngas produced. The steam to biomass ratio was operated at 0 to 0.6 at the fuel flow rate of $1.5 \mathrm{~kg} / \mathrm{hr}, 700^{\circ} \mathrm{C}$, pressure of 1 bar and ER of 0.2 for biomass feedstocks used for the simulation studies. Increasing steam flow rate from 0 to $0.6 \mathrm{~kg} / \mathrm{hr}$ increased both $\mathrm{H}_{2}$ concentration (from $26 \%$ to $30 \%$ ) and $\mathrm{CO}_{2}$ (from $1.4 \%$ to $3.3 \%$ ) (Figure 8 ). In contrast, increasing steam flow rate decreased the concentration of $\mathrm{CO}$ (from $52.5 \%$ to $40 \%$ ) and $\mathrm{CH}_{4}$ (from $17.7 \%$ to $5.7 \%$ ). In the case of rice husk simulation process, the same operating parameters were used and increasing steam flow rate increased the concentration of $\mathrm{CO}_{2}(0.97 \%$ to $2.6 \%)$ and $\mathrm{H}_{2}(22.8 \%$ to $28.4 \%)$. In contrast to $\mathrm{CO}_{2}$ and $\mathrm{H}_{2}$, the concentration of the other two gases declined, i.e., $\mathrm{CH}_{4}$ from $20.7 \%$ to $6.9 \%$ and $\mathrm{CO}$ from $54.9 \%$ to $41.9 \%$. The syngas composition generally decreased with increasing steam flow rate.

The syngas composition produced from coffee bean husk was better than that from the rice husk (Figure 8). This could perhaps be the case because $\mathrm{H}_{2}$ composition was high at lower steam flow rates.

As steam to biomass ratio increased, the lower heating value of the produced gas decreased (Figure 9). At the lower steam to biomass ratio, the lower heating value of the biomass feedstocks reached its maximum value. The heating values of the biomass decreased at the lower steam to biomass ratio (Figure 9). Coffee husk gave the highest heating value of $46,192.6 \mathrm{~kJ} / \mathrm{kg}$ at the minimum steam to biomass ratio. Similarly, rice husk gave the highest heating value of $43,165.41 \mathrm{~kJ} / \mathrm{kg}$ at the same steam to biomass ratio. This implies that both biomasses had higher heating value at lower steam to biomass ratio. Although the trend was the same for the two biomasses, coffee bean husk performed generally better than the rice husk. 


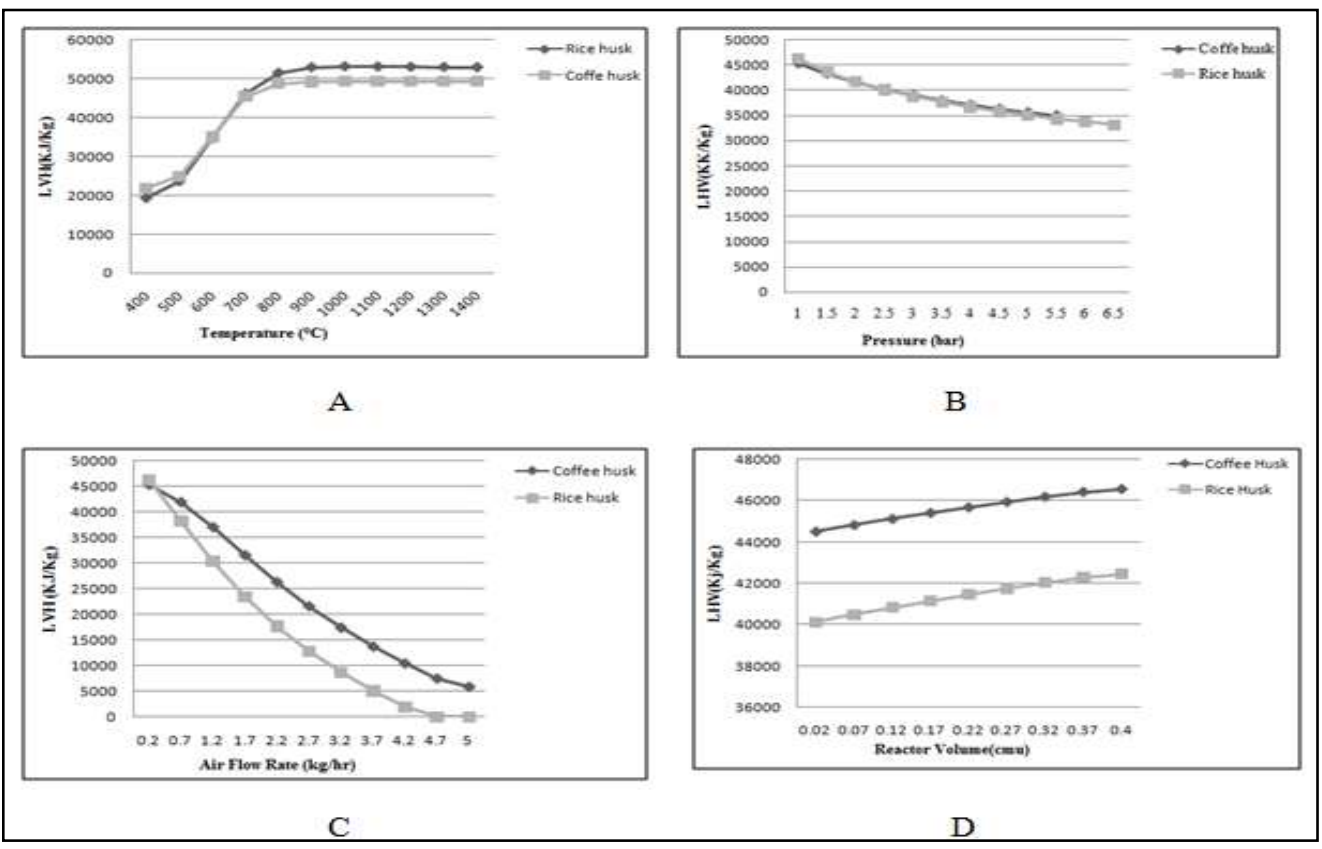

Figure 7. The effects of different parameters on heating value of syngas (A) Temperature; (B) Pressure; (C) Air flow rate; (D) Reactor volume. 
Bedewi Bilal et al.

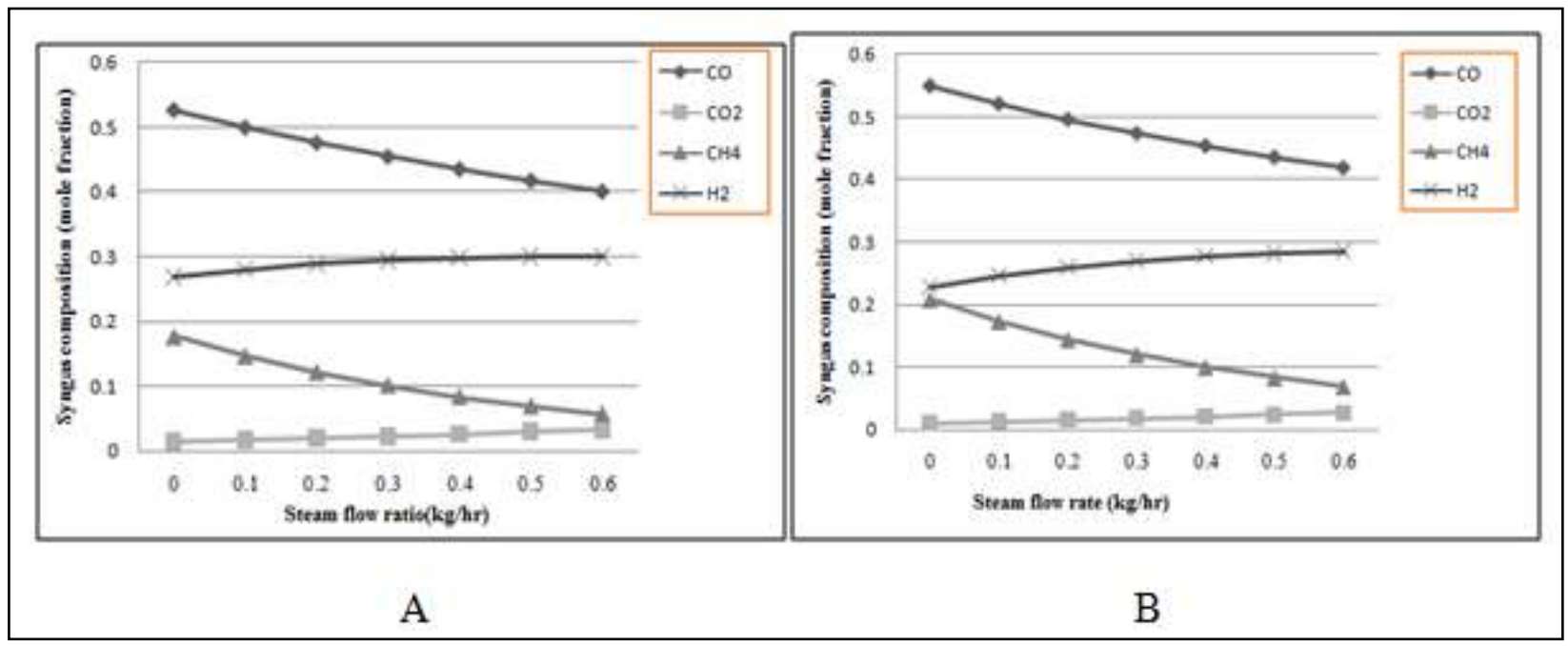

Figure 8. The effect of steam on the syngas production (A) for coffee bean husk and (B) for rice husk 


\section{CONCLUSION}

From the current study, it was generally concluded that the higher the gasification temperature, the lower the heating value, the heat conversion efficiency and the carbon conversion. The effective temperature of the gasifier for the production of syngas should be $800^{\circ} \mathrm{C}$ at the air equivalent ratio of 0.2 . Also, results indicate that air equivalent ratio affected syngas production; i.e., higher air equivalent ratio increased carbon conversion while it decreased the lower heating value. At the smaller air equivalent ratio, the lower heating value was maximum, which then decreased as the ratio increased. The lower air equivalent ratio implies the higher concentration of producer gases. High moisture content may not improve the gasification process. Furthermore, an increase in moisture content reduced heating value of the produced syngas. On the other hand, higher moisture content concentration increased carbon conversion efficiency at the lower air equivalent ratio.

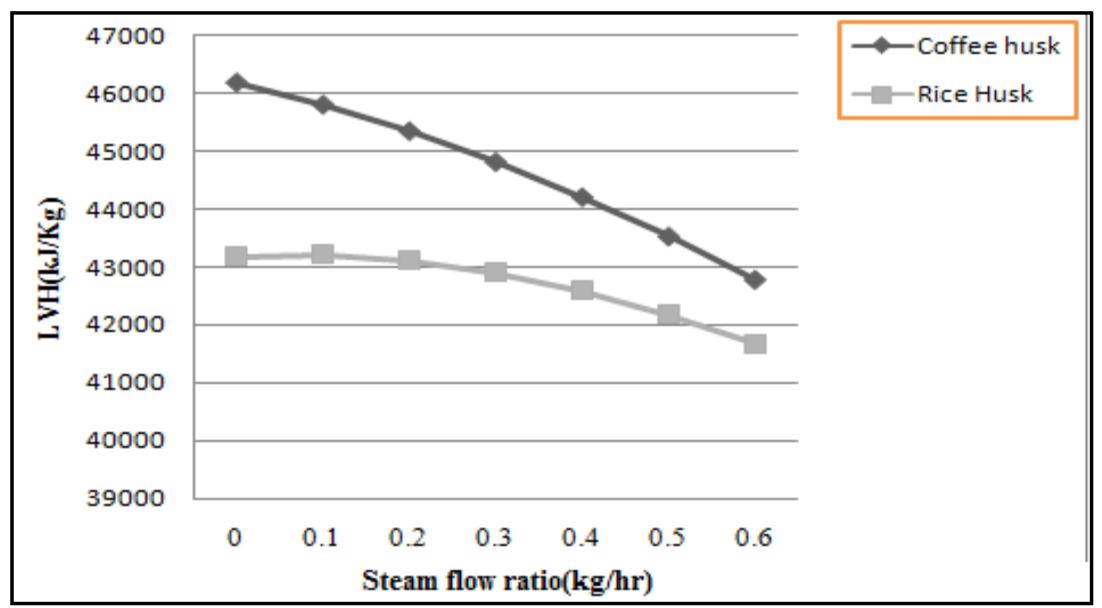

Figure 9. The effect of steam on the LHV of syngas 


\section{ACKNOWLEDGEMENTS}

The authors are highly thankful to the Faculty of Chemical and Food Engineering, Bahir Dar Institute of Technology, Bahir Dar University, Bahir Dar, Ethiopia, for they allowed us to use laboratory facilities during the conduct of this research.

\section{REFERENCES}

Alison, R., Steve, R., Glenn, C and Kurt, S. (2018). Towards Sustainable Energy: The current Fossil Fuel problem and the prospects of Geothermal and Nuclear power. Stanford Material. https://web.stanford.edu/class/e297c/trade_environment/energy/hfossil.html (accessed March 16, 2018).

Andre, F. (2006). Modern biomass conversion technologies. Mitigation and Adaptation Strategies for Global Change 11(2): 343-375.

ASTM (2016). International Standards Worldwide. ASTM. https://www.astm.org (accessed on March 22, 2017).

Avdhesh, K.S. (2008). Equilibrium and kinetic modeling of char reduction reactions in a downdraft biomass gasifier: A comparison. Solar Energy 82(10): 918-928.

Ayhan, D. (2004). Combustion characteristics of different biomass fuels Author links open overlay panel. Progress in Energy and Combustion Science 30(2): 219-230.

Bridgwater, A. (2003). Renewable fuels and chemicals by thermal processing of biomass. Chemical Engineering Journal 91(2-3): 87-102.

Buljit, B., Sankar, C., Peeush, K., Pinakeswar, M and Vijayan, S. M. (2013). Comparative evaluation of kinetic, equilibrium and semi-equilibrium models for biomass gasification. International Journal of Energy and Environment 4(4):581-614.

Buekens, A.G and Schoeters, J.G. (1985). Modeling of biomass gasification. In: Fundamentals of thermo-chemical biomass conversion, pp 619-689 (Overend, R.P., Milne, T.A. and Mudge, K.L., eds.), Elsevier Applied Science Publishers, London, United Kingdom.

Chen, C., Jin, Y., Yan, J and Chi, C. (2010). Simulation of municipal solid waste gasification for syngas production in fixed bed reactors. Journal of Zhejiang University-Science and Applied Physics and Engineering 11(8): 619-628.

Chittaranjan, P. (2012). Aspen Plus Simulation and experimental studies on biomass gasification. B. Tech Thesis, National Institute of Technology, Rourkela, India.

Cornelius, E.A., Rajan, K.T and Britt, M.H. (2015). Simulation of Simplified Model for Kinetics of Biomass Gasification. In: Proceedings of the $56^{\text {th }}$ Simulation of simplified model for Reaction Kinetics in Biomass Gasification, pp. 81-89, Linköping, Sweden.

Chunshan, L and Kenzi, S. (2009). Tar property, analysis, reforming mechanism and model for biomass gasification-an overview. Renewable and Sustainable Energy Reviews 13 (3):594-604

Dasappa, S. (2011). Potential of biomass energy for electricity generation in sub-Saharan Africa. Energy for Sustainable Development 15:203-213

Emma, B.H., Dente, M and Ranzi, E. (2011). Detailed Kinetics of the Pyrolysis and Oxidation of Anisole. Chemical Engineering Transactions 24:61-66.

Ergudenler, A. (1993). Gasification of wheat straw in a dual-distributor type fluidized bed reactor. Ph.D., thesis, Technical University of Nova Scotia, Canada 
Harmandeep, S., Pawan, K.S and Balwinder, S.S. (2013). Evaluation and characterization of different biomass residues through proximate and ultimate analysis and heating value. Asian Journal of Engineering and Applied Technology 2: 6-10

Ke, S. (2014). Optimization of biomass gasification reactor using Aspen Plus. M.Sc., thesis, Telemark University College, Norway.

Lv, P.M., Xiong, Z.H., Chang, J., Wu, C.Z., Chen, Y and Zhu, J.X. (2004). An experimental study on biomass air-steam gasification in a fluidized bed. Bio-resource Technology 95:95-101

Lars, W and Torbjörn, N. (2001). Heating Value of Gases from Biomass Gasification. Report prepared for: IEA Bioenergy Agreement, Task 20 Thermal Gasification of Biomass. www.ieatask33.org/app/webroot/files/file/publications/HeatingValue.pdf (Accessed March, 10, 2018)

Maria, P.A. (2011). Performance modelling and validation of biomass gasifiers for trigeneration plants. $\mathrm{PhD}$ thesis, Universitat Rovirai Virgili, Tarragona, Spain.

Maria, P.A., Joan, C.B and Alberto, C. (2010). Review and analysis of biomass gasification models. Renewable and Sustainable Energy Reviews 14(9): 2841-2851

Muilenburg, M., Yunve, S and Ratner, A. (2011). Computational modeling of the combustion and gasification zones in a downdraft gasifier. In: ASME 2011 International Mechanical Engineering Congress and Exposition, pp 151-158, Denver, Colorado, USA.

Oliver, K., Sardor, M., Michael, G., Claude, F.G and Horn, R. (2011). Measurement and analysis of spatial reactor profiles in high temperature catalysis research. Chemical Engineering and Processing: Process Intensification 50(10):998-1009.

Van der Stelt, M.J.C., Gerhauser, H., Kiel., J.H.A and Ptasinski, K.J. (2011). Biomass upgrading by Torre faction for the production of biofuels: A review. Biomass and Bio-energy 35(9):37483762

Sadaka, S. (2008). Pyrolysis. Center for Sustainable Environmental Technologies 10: 15-25

Sadaka, S.S., Ghaly, A.E and Sabbah, M.A. (2002). Two phase biomass air-steam gasification model for fluidized bed reactors: Part I — model development. Biomass and Bio-energy 22(6): 439-462

Schuster, G., Loffler, G., Weigl, K and Hofbauer, H. (2001). Biomass steam gasification - an extensive parametric modeling study. Bio-resource Technology 77(1): 71-79.

Sharmina,B., Rasul, M.G., Akber, D and Ramzan, N. (2013). Performance Analysis of an Integrated Fixed Bed Gasifier Model for Different Biomass Feedstocks. Energies 6(12): 650824.

Zhenga, L and Furimsky, E. (2003). ASPEN simulation of cogeneration plants. Energy Conversion and Management 44(11): 1845-51. 


\section{List of Abbreviations:}

$\begin{array}{ll}\text { AC } & \text { Ash content } \\ \text { ASPEN } & \text { Advanced Project System for Process Engineering } \\ \text { ASTM } & \text { American Society for Testing Materials } \\ \text { CFD } & \text { Computational fluid dynamics } \\ \text { CH } & \text { Coffee husk } \\ \text { ER } & \text { Equivalence ratio } \\ \text { ER } & \text { Equivalent ratio } \\ \text { FC } & \text { Fixed carbon } \\ \text { Kg } & \text { Kilo gram } \\ \text { KJ } & \text { Kilo joule } \\ \text { LHV } & \text { Lower heating value } \\ \text { MIT } & \text { Massachusetts Institute of Technology } \\ \text { MJ } & \text { Mega joule } \\ \text { MPa } & \text { Mega pascal } \\ \text { PFC } & \text { Percentage fixed carbon } \\ \text { PMC } & \text { Percentage moisture content } \\ \text { PVM } & \text { Percentage volatile matter } \\ \text { SOFC } & \text { Solid oxide fuel cell } \\ \text { VM } & \text { Volatile matter }\end{array}$

